\title{
Plasticity of flower longevity in alpine plants is increased in populations from high elevation compared to low elevation populations
}

\author{
Judith Trunschke ${ }^{1,2}$ (1) Jürg Stöcklin ${ }^{1}$
}

Received: 5 April 2016/Accepted: 15 September 2016/Published online: 30 September 2016

(C) The Author(s) 2016. This article is published with open access at Springerlink.com

\begin{abstract}
Flower longevity is an adaptive trait, optimized to balance reproductive success against the costs of flower maintenance. The trait is highly plastic in response to pollination success, and numerous studies report increased flower longevity in high elevation environments, where diversity, abundance, and activity of pollinators are low. However, few studies have experimentally investigated how flower longevity varies with pollination intensity within and among populations. We studied flower longevity of six alpine species under three pollination intensity treatments (hand-pollination, natural pollination, pollinator exclusion) at $1600 \mathrm{~m}$ vs. $2600 \mathrm{~m}$ a.s.l. at the Furka Pass, Central Swiss Alps. We hypothesized, (1) that flower longevity is generally increased in population at high elevation, and (2) that the increase in flower longevity when pollination fails is stronger in populations at high elevation compared to low elevation. Hand-pollination did not decrease flower longevity in any of the studied populations and rarely increased natural seed production suggesting no pollination limitation at both elevations. This was supported by similar pollinator visitation rates, pollinator efficiency, and pollination
\end{abstract}

Electronic supplementary material The online version of this article (doi:10.1007/s00035-016-0176-4) contains supplementary material, which is available to authorized users.

Judith Trunschke

judith.trunschke@ebc.uu.se

1 Plant Ecology, Institute of Botany, University of Basel, Schönbeinstrasse 6, 4056 Basel, Switzerland

2 Present Address: Plant Ecology and Evolution, Department of Ecology and Genetics, Evolutionary Biology Centre, Uppsala University, Norbyvägen 18D, SE-752 36 Uppsala, Sweden effectivity. Pollinator exclusion significantly increased flower longevity, but only in populations of three species at low elevation, whereby in all populations of the six species at high elevation, indicating a higher plasticity of flowers in populations at high elevation compared to populations from lower elevation. We suggest that the higher plasticity of flower longevity in alpine populations is of advantage in their unpredictable pollination environment: Increased flower longevity compensates for low pollination in unsuitable periods guaranteeing a minimum reproduction, while the capacity to senescence rapidly after successful pollination saves redundant floral costs in suitable periods.

Keywords Pollinator visitation rate - Pollen deposition . Seed production - Spatial variation - Population variation . Phenotypic plasticity $\cdot$ Pollinator adaptation

\section{Introduction}

Flower longevity is defined as the time in which a flower remains open and functional, and is a crucial feature for a plants' reproductive success as it directly determines the time available for pollinator visitations, and, thus, pollen removal and deposition (Primack 1985; Ashman and Schoen 1994). However, flowers are costly organs, and their longevity might be determined to balance the rate at which male and female fitness accrue over time against the daily costs of floral maintenance, with short-living flowers when fitness accrual rates and maintenance costs are high and long-living flowers when fitness accrual rates and maintenance costs are low (Schoen and Ashman 1995). Individual flower longevity is a highly plastic trait, which can alter in immediate response to external environmental biotic (the quantity and 
quality of pollination) and abiotic (availability of water, temperature and light) conditions. Flower longevity might be elongated if pollinators are scarce and pollination success is low. Contrary, flower longevity might be limited by the high carbon (Ashman and Schoen 1997) and water (Teixido and Valladares 2015) demand of flower development and the maintenance of reproductively functional flowers. Thus, temporal and spatial variation of both the biotic and abiotic environment interplays in determining potential and actual flower longevities in natural populations resulting in amongand within-population variation in flower longevity.

Experimentally modified rates of pollen removal and/or receipt can be used to estimate the minimum flower longevity by maximizing pollination success with supplemental handpollinations and the maximum flower longevity by minimizing pollination success with pollinator exclusion (Devlin and Stephenson 1984). Both field and greenhouse studies demonstrated a strong negative correlation between flower longevity and experimental manipulation of pollination success (Devlin and Stephenson 1984; Richardson and Stephenson 1989; Evanhoe and Galloway 2002; Clark and Husband 2007; Castro et al. 2008). In natural populations, several studies have demonstrated increasing flower longevity along either environmental (Bingham and Orthner 1998; Yasaka et al. 1998; Blionis et al. 2001; Blionis and Vokou 2001; Giblin 2005; Ægisdottir and Thorhallsdottir 2006; Lundemo and Totland 2007) or seasonal (Totland 1994a; Rathcke 2003) declining gradients of pollinator availability.

The composition and activity of pollinator communities varies considerably among biogeographic regions (Primack and Inouye 1993; Olesen and Jordano 2002). In high arctic and alpine environments pollinator diversity, abundance and activity is often low due to unfavorable conditions for insect life (Arroyo et al. 1982, 1985; Warren et al. 1988; McCall and Primack 1992; Totland 1994b; Bingham and Orthner 1998; Blionis and Vokou 2001) leading to highly variable and often scarce pollination success. Because of the commonly strong pollen limitation of reproduction in alpine plants (Billings 1974; Stenström and Molau 1992; Elberling 2001; Totland and Sottocornola 2001; Lundemo and Totland 2007; but see Totland 1997; Totland and Eide 1999; Totland 2001; Garcia-Camacho and Totland 2009), flower longevity often increases with increasing elevation (Arroyo et al. 1981; Primack 1985; Bingham and Orthner 1998; Blionis and Vokou 2001; Fabbro and Körner 2004; Giblin 2005; Ægisdottir and Thorhallsdottir 2006; Lundemo and Totland 2007). Contrasting results, however, due to alternative pollination strategies (Arroyo et al. 2006) or specific pollinator behavior (Duan et al. 2007) suggest that variation in flower longevity is highly context-dependent, but few studies have directly characterized the actual pollination environment. Context-dependent variation in the plastic response of flower longevity can be easily examined by experimentally manipulating the success of pollination in populations occurring in contrasting pollination environments. However, studies addressing the entire possible range of flower longevity to reveal patterns of phenotypic plasticity among natural populations are limited (Blionis and Vokou 2001; Giblin 2005; Ægisdottir and Thorhallsdottir 2006; Duan et al. 2007). It needs to be further investigated whether generally increased and/or higher plasticity of flower longevity are adaptive features of high elevation populations to efficiently balance flower costs and pollination success in this unpredictable pollination environment.

In the present study, we used a combination of natural elevational variation in pollination intensity between populations of different species and experimentally modified pollination success within populations to address whether (1) flower longevity of alpine species is generally increased in populations at high elevation compared to populations at lower elevation, and (2) the increase in flower longevity when pollination fails is stronger in populations at high elevation compared to populations at low elevation. To test the hypotheses of a general increase and a higher plasticity of flower longevity in high elevation populations, we studied two populations for each of six alpine species occurring at a difference of $1000 \mathrm{~m}$ elevation in the Central Swiss Alps, and experimentally manipulated pollination success at both elevations by three pollination treatments: open control pollination, supplemental hand-pollination, and pollinator exclusion. In addition, we directly quantified and qualified differences in the pollination environment between the high elevation and the low elevation location by measuring pollinator activity, pollination efficiency, and pollination effectivity in all study populations to address if: (a) high elevation populations receive fewer pollinator visitations, (b) they have fewer pollen grains deposited on their stigmas and (c) they subsequently produce fewer seeds during the same time intervals in which flowers are available for pollination.

\section{Materials and methods}

\section{Study sites and study species}

The study was conducted between June and September 2009 at the Furka Pass in the Urseren Valley, Central Swiss Alps. We selected two similar grassland regions of approximately $100 \mathrm{~m}^{2}$ : one at an elevation of $1600 \mathrm{~m}$ located near the community of Realp, and another at an elevation of $2600 \mathrm{~m}$ up the Furka Pass, near the research and education center ALPFOR. The two regions are hereafter called low and high elevational location. Both locations consist of herb-rich alpine meadows of similar co-flowering plant communities, but show differences in phenology with a much shorter and 
more pronounced flowering peak at the high elevation location. Both locations are used for agricultural purposes during the summer months, with cows grazing at the lower location and sheep being present at the high elevation location. We used electric fencing to prevent disturbance by grazing and trampling when necessary.

For the study, we selected populations of six alpine plant species from different angiosperm families that occur in dense populations at the low and the high elevation location: Campanula scheuchzeri VILL. (Campanulaceae), Euphrasia montana JORD. (Orobanchaceae), Homogyne alpina (L.) CASS. (Asteraceae), Potentilla aurea L. (Rosaceae), Primula farinosa L. (Primulaceae), and Trifolium alpinum L. (Fabaceae). While E. montana is an annual plant, the five others are perennial. The latter are predominantly outcrossing and rely on insect visitations for successful pollen transfer between flowers. The Genus Euphrasia is facultatively outcrossing and less dependent on pollinator service; it is self-compatible and capable of autonomous self-pollination (Gomez 2002; Liebst and Schneller 2005).

At the low elevation location, fieldwork was performed from early June throughout the summer until the end of August. At high elevation, fieldwork started immediately after snowmelt in early July and was continued until the beginning of September. All observations and experiments were carried out when each of the studied populations was in peak flowering (Table 1).

\section{Flower longevity and reproductive success}

To estimate the phenotypic plasticity of flower longevity, we selected 15 groups of three individual plants (one for each treatment) in each of the 12 populations (a total of 540 plants; $N=15$ per treatment per population), and on each plant we marked one flower in the early bud stage. In each group one plant was, then, randomly assigned to one of the following three pollination treatments that were used to vary the intensity of pollination, i.e., the amount of conspecific pollen deposited on a flower's stigmatic surface (Ashman and Schoen 1994): (1) open flowers that received natural levels of pollination, (2) open flowers that received in addition supplemental hand-pollination, and (3) bagged flowers that received no pollination at all. Supplemental pollinated flowers were used to determine the minimal possible flower longevity when pollen deposition is high, whereas pollinator exclusion was used to determine the maximum possible flower longevity when pollination fails, i.e., when no outcross-pollen is deposited on the stigma (Devlin and Stephenson 1984; Evanhoe and Galloway 2002). The realized flower longevity is accordingly estimated by natural open control pollination and is expected to be somewhere in the range between maximum and minimum flower longevity depending on the natural variation in pollination success. For the supplemental pollination treatment, all hand-pollinations were performed by carefully striking anthers from flowers of one to three different donor plants over the receptive stigma of the focal flower. All donor plants were selected in a minimum distance of $5 \mathrm{~m}$ from recipient individuals to avoid pollen from genetically related neighbors. This procedure was repeated on two consecutive days as soon as the stigma of the recipient flowers appeared visually receptive (styles elongated, stigmatic lopes exposed and shinny). For the pollinator exclusion treatment, we prevented visitation of potential pollinators by bagging the entire plant with $5 \times 10 \mathrm{~cm}$ sized bags of mosquito net throughout the observation period from bolting until flowers were senescent. All focal flowers were inspected daily to record each flower's fate from the early bud stage to the initiation of a fruit. In the Compositae species Homogyne entire inflorescences (flower heads) were monitored for their longevity rather than individual flowers. Flower longevity was measured as the number of days that flowers were fully open, stigmas were available for pollination, and appeared receptive as assessed by eye. In addition, for each plant included in the experiment, we recorded the total number of flowers to check for differences

Table 1 Study period, number of flowers per plant, and flower longevity (mean \pm SD) of open-pollinated control plants of six alpine species studied at two elevations at the Furka Pass, Central Swiss Alps, in summer 2009

\begin{tabular}{|c|c|c|c|c|c|c|}
\hline \multirow[t]{2}{*}{ Study species } & \multicolumn{2}{|l|}{ Study period } & \multicolumn{2}{|l|}{ No. of flowers } & \multicolumn{2}{|c|}{ Flower longevity } \\
\hline & Low elevation & High elevation & Low elevation & High elevation & Low elevation & High elevation \\
\hline C. scheuchzeri & 9 Jul-7 Aug & 12 Aug-27 Aug & $1.1 \pm 0.3^{\mathrm{a}}$ & $1.0 \pm 0.0^{\mathrm{a}}$ & $4.5 \pm 1.1^{\mathrm{a}}$ & $4.3 \pm 0.6^{\mathrm{a}}$ \\
\hline E. montana & 1 Aug-9 Aug & 1 Aug-13 Aug & $23.7 \pm 13.9^{\mathrm{a}}$ & $8.2 \pm 3.6^{\mathrm{b}}$ & $3.2 \pm 1.4^{\mathrm{a}}$ & $5.1 \pm 1.1^{\mathrm{b}}$ \\
\hline H. alpina & 3 Jun-27 Jun & 2 Aug-28 Aug & $46.7 \pm 6.9^{\mathrm{a}}$ & $47.0 \pm 6.5^{\mathrm{a}}$ & $17.6 \pm 1.9^{\mathrm{a}}$ & $14.5 \pm 2.9^{\mathrm{b}}$ \\
\hline P. aurea & 2 Jun-15 Jun & 30 Jun-7 Aug & $6.1 \pm 3.7^{\mathrm{a}}$ & $2.2 \pm 1.2^{\mathrm{b}}$ & $3.1 \pm 1.2^{\mathrm{a}}$ & $3.2 \pm 1.0^{\mathrm{a}}$ \\
\hline P. farinosa & 10 Jun-28 Jun & 7 Jul-28 Jul & $7.6 \pm 2.8^{\mathrm{a}}$ & $8.4 \pm 3.0^{\mathrm{a}}$ & $9.3 \pm 2.2^{\mathrm{a}}$ & $16.1 \pm 2.3^{\mathrm{b}}$ \\
\hline T. alpinum & 3 Jun-19 Jun & 29 Jul-10 Aug & $10.6 \pm 1.6^{\mathrm{a}}$ & $10.4 \pm 2.0^{\mathrm{a}}$ & $3.4 \pm 1.2^{\mathrm{a}}$ & $4.2 \pm 1.8^{\mathrm{a}}$ \\
\hline
\end{tabular}

For each species significant differences between populations are examined by $t$ test at $P<0.05$, and indicated by values not sharing the same letter 
in flower production between populations at different elevations. At the end of the flowering period, we harvested the fruits of all experimental flowers and stored them in individual envelopes for later counts of seed production as measurement of pollination and reproductive success.

About $30 \%$ of all fruits were lost or destroyed due to strong winds or occasional snowfall, resulting in reduced and slightly unbalanced sample sizes. The number of seeds produced by each experimental flower was counted using a dissecting microscope (Leica Z30E). Since calculation of seed:ovule ratios was not possible in the cases of Campanula and Primula, the total number of fully developed seeds rather than the percentage of fertilized ovules was used for all species in all analyses.

\section{Pollination regime at low and high elevation}

\section{Pollinator activity}

To examine differences in the quantity of pollination, we measured pollinator activity as the number of insect visitations to individual flowers per hour. We observed flower visitations on several consecutive days, excluding those of unfavorable weather conditions for insect activity (strong winds and heavy rainfalls), but including some foggy days that often occurred at the high elevation location. All observations were done between 09.00 and $17.00 \mathrm{~h}$, when pollinator activity was highest. All populations were visited randomly once a day during their peak flowering period. During each observation period, we simultaneously monitored groups of five flowers in close proximity for a period of $20 \mathrm{~min}$. Visitations to flowers were only recorded when the visiting insect was noticed to touch either the anthers and/or the stigmas of focal flowers, and re-visitations of the same insect were recorded as two separate visits. The visitation rate to single flowers per hour was calculated by dividing the total number of recorded visits per hour by the number of flowers observed. Since insect identification in the field was often difficult and imprecise, pollinating insects were broadly categorized into five distinguished groups: bees (Apiformes), bumble bees (Bombus), flies (Diptera), butterflies (Lepidoptera), hoverflies (Syrphidae), and undefined others such as ants or caterpillars from which pollinating capacity is unknown. For each observation period the date and time of day as well as weather conditions were recorded.

\section{Pollen deposition and seed production}

To examine differences in the quantity and quality of pollination between populations at the two elevations more precisely, we measured both the efficiency and effectiveness of pollination within defined time periods. Pollen deposition is determined as the number of pollen grains delivered on a stigma and is used to assess the quantity and the quality of pollination (pollination efficiency), whereas seed or fruit production is used to determine the effectiveness of pollination (Dafni et al. 2005). To do so, we marked in each population two new independent groups of 30 flowers in the early bud stage (a total of 360 flowers), on the one hand to score pollen deposition and on the other hand to measure seed production. All experimental plants were covered with a mosquito net prior to the experiment to control the duration that flowers were presented to pollinators. As soon as flowers opened and stigmatic surfaces appeared receptive (see definition above), the bags were removed and pollinator visitation was allowed for either 1 or 2 days (resulting in $N=15$ flowers per species per site per time period).

The flowers used to estimate pollen deposition were immediately harvested after flowers have been presented to pollinators and emasculated for transport conditions. The stigmas were then either immediately prepared under a dissecting microscope or otherwise temporally stored in a fridge at $5{ }^{\circ} \mathrm{C}$ until further processing. Since the stigmas of Campanula are too large, they were separated into their three stigmatic lobes before further handling. Stigmas were colored in a 1:3 mixture of Methylen-Green Phloxin B stain for 1-5 min, depending on the species. This procedure colorizes germinated pollen grains in green, while non-germinated pollen grains are colored in red (Dafni et al. 2005), which makes deposited pollen grains clearly visible under a light microscope. However, for the purpose of the present study, we did not further distinguish between germinated and non-germinated pollen grains. After coloration stigmas were gently squashed in a drop of gelatin on a microscope slide (Beattie 1971). All slides were preserved by carefully encircling the coverslip with nail varnish and stored for later analysis in the laboratory. The number of deposited conspecific and heterospecific pollen grains per stigma was counted under a light microscope (Leitz HM-LUX 3) using a pollen reference collection that was produced at the start of the experiment. The average pollen deposition was calculated as the mean number of conspecific pollen grains per stigma per flower. In the case of Potentilla and Homogyne (species that have more than one stigma per flower/inflorescence) means of three stigmas of random locations within a flower were representatively used.

The flowers used to assess seed production after 1 and 2 days of pollination were subsequent to pollinator presentation re-bagged and bagging was maintained until fruit maturation. Mature fruits were then collected and temporarily stored in individual envelopes for later preparation in the laboratory. The number of fully developed seeds was counted under a dissecting microscope (Leica Z30E). Again, we used the total number of seeds developed instead of 
seed:ovule ratios, since this calculation was not possible for the species Campanula and Primula.

\section{Statistical analysis}

The effect of elevation and pollination treatment on flower longevity and reproductive success was analyzed using a linear mixed effect model on maximum likelihood (LME, package nlme; Pinheiro et al. 2009). Flower longevity and seed production were defined as response variables, respectively, and in both models species, elevation and pollination treatment, including all interactions, were specified as fixed explanatory variables. Grouping of flowers was included as a random factor of spatial structure based on lower AIC (Akaike information criterion) and BIC (Bayesian information criterion) values in a test of goodness of fit between models with and without a random component. Seed production was square root transformed prior to analysis. Following both models, a priori contrasts were used to test for differences of flower longevity and seed production between natural and treated flowers for each population separately. In addition, for testing the effect of elevation on plasticity in flower longevity, we calculated for each flower group the pairwise differences of flower longevity between the bagged and the supplemental pollinated treatment, as this should reflect the maximum range of possible flower longevities. We then used a mixed effect model with the calculated differences of flower longevity as response variable, elevation as fixed factor and species as random factor to test for a significant effect of elevation.

Differences in visitation rates between the two study sites were tested for each species separately by the use of nonparametric Wilcoxon rank sum test, because the data of visitation frequencies were not normally distributed.

To test for differences in success of pollination, that is temporally defined pollen deposition and seed production between the populations at low and high elevation, we used a generalized linear model (GLM, package nlme; Pinheiro et al. 2009). The models included pollen deposition and seed production as response variables, respectively, and species, elevation and the duration of flower exposure as explanatory variables including all interactions. We also explored a model on elevation and pollination duration for each species separately. Because of overdispersion, a quasi-poisson distribution with log-link was used in all analysis, in which the variance is given by $\Phi \times \mu$, where $\mu$ is the mean and $\Phi$ the dispersion parameter (Zuur et al. 2009).

All statistical analyses were performed using the statistical software $\mathrm{R}$ version 2.10.0 (R Development Core Team 2008). All values in text and tables are presented as mean $\pm \mathrm{SD}$, and all values in graphics are given as mean \pm SE. All differences mentioned are statistically significant at $P<0.05$.

\section{Results}

\section{Species differences}

As expected average flower longevity, visitation rate, pollen deposition, and seed production differed significantly among the six study species. Flower longevity was as short as $3.6 \pm 0.1$ days in Potentilla aurea and up to $16.8 \pm 0.4$ days in Homogyne alpina (means across elevation and pollination treatments; Tables 1, 2; Fig. 1). Likewise, the average seed production per flower or flower head, respectively, differed among species with $0.6 \pm 0.1$ seeds produced for Trifolium alpinum to $17.8 \pm 1.5$ seeds produced for Homogyne (means across elevation and pollination treatments; Table 2; Fig S1).

Flowers of the six species were visited by pollinators with different frequencies: most pollinator visits per hour were counted on flowers of Campanula scheuchzeri with $9.3 \pm 1.0$ visits, whereas the visiting frequency was lowest for Trifolium with $0.9 \pm 0.3$ visits per hour (means across elevation; Table S1; Fig. 2a). The number of pollen grains delivered to recipient stigmas differed significantly among species with the lowest average pollen deposition found for Primula $(22 \pm 6)$ and the highest average pollen deposition recorded for Campanula (1152 \pm 62 ; means across elevation and time periods; Tables S2 and S3; Fig. 2b). Similarly, the number of seeds produced per unit time differed significantly among species. Campanula had the highest average seed production (52.5 \pm 8.8$)$ and Primula farinosa had the lowest seed production $(1.3 \pm 0.5$; means across elevations and time periods; Tables S2 and S3; Fig. 2c).

\section{Flower longevity}

The mean realized flower longevity (open-pollinated control plants) differed significantly between populations at the two elevations, but in variable direction among species as indicated by a significant interaction term of species and elevation (Table 2). Realized flower longevity was increased at high elevation compared to low elevation in two species (Primula, Euphrasia; $t$ test, $P<0.05$ ), similar in three species Campanula, Potentilla and Trifolium ( $t$ test, $P>0.05$ ), and shortened in one species (Homogyne; $t$ test, $P<0.05$; Table 1; Fig. 1).

Overall, pollination intensity treatments significantly affected flower longevity (Table 2), whereby hand-pollination did not shorten flower longevity in any of the studied populations, while pollinator exclusion increased flower longevity (post hoc contrasts, Fig. 1). However, the effect of pollinator exclusion was variable among species and among species for the two elevation as indicated by significant elevation $\times$ treatment and species $\times$ elevation $\times$ treatment interactions (Table 2). Flower longevity 
Table 2 The effect of species identity, elevation (low vs. high elevation), and pollination intensity (open-pollinated, supplemental pollinated, pollinator exclusion) and their interactions on flower longevity and seed set in six alpine species studied at two elevations at the Furka Pass, Central Swiss Alps, in summer 2009

\begin{tabular}{|c|c|c|c|c|c|c|}
\hline \multirow[t]{2}{*}{ Factor } & \multicolumn{3}{|c|}{ Flower longevity } & \multicolumn{3}{|l|}{ Seed set } \\
\hline & $\mathrm{Df}_{(\text {num,den) }}$ & $F$ & $P$ & $\mathrm{Df}_{(\text {num,den) }}$ & $F$ & $P$ \\
\hline (Intercept) & 1,285 & 6729.41 & $<0.0001$ & 1,246 & 368.30 & $<0.0001$ \\
\hline Species & 5,168 & 595.39 & $<0.0001$ & 5,161 & 202.41 & $<0.0001$ \\
\hline Elevation & 1,168 & 90.22 & $<0.0001$ & 1,161 & 0.03 & 0.854 \\
\hline Treatment & 2,285 & 88.41 & $<0.0001$ & 2,246 & 164.90 & $<0.0001$ \\
\hline Species $\times$ elevation & 5,168 & 47.91 & $<0.0001$ & 5,161 & 15.40 & $<0.0001$ \\
\hline Species $\times$ treatment & 10,285 & 9.14 & $<0.0001$ & 10,246 & 23.70 & $<0.0001$ \\
\hline Elevation $\times$ treatment & 2,285 & 6.24 & 0.002 & 2,246 & 2.37 & 0.096 \\
\hline Species $\times$ elevation $\times$ treatment & 10,285 & 2.80 & 0.002 & 10,246 & 6.54 & $<0.0001$ \\
\hline
\end{tabular}

Significant differences are examined from mixed effect models at $P<0.05$ and indicated in bold

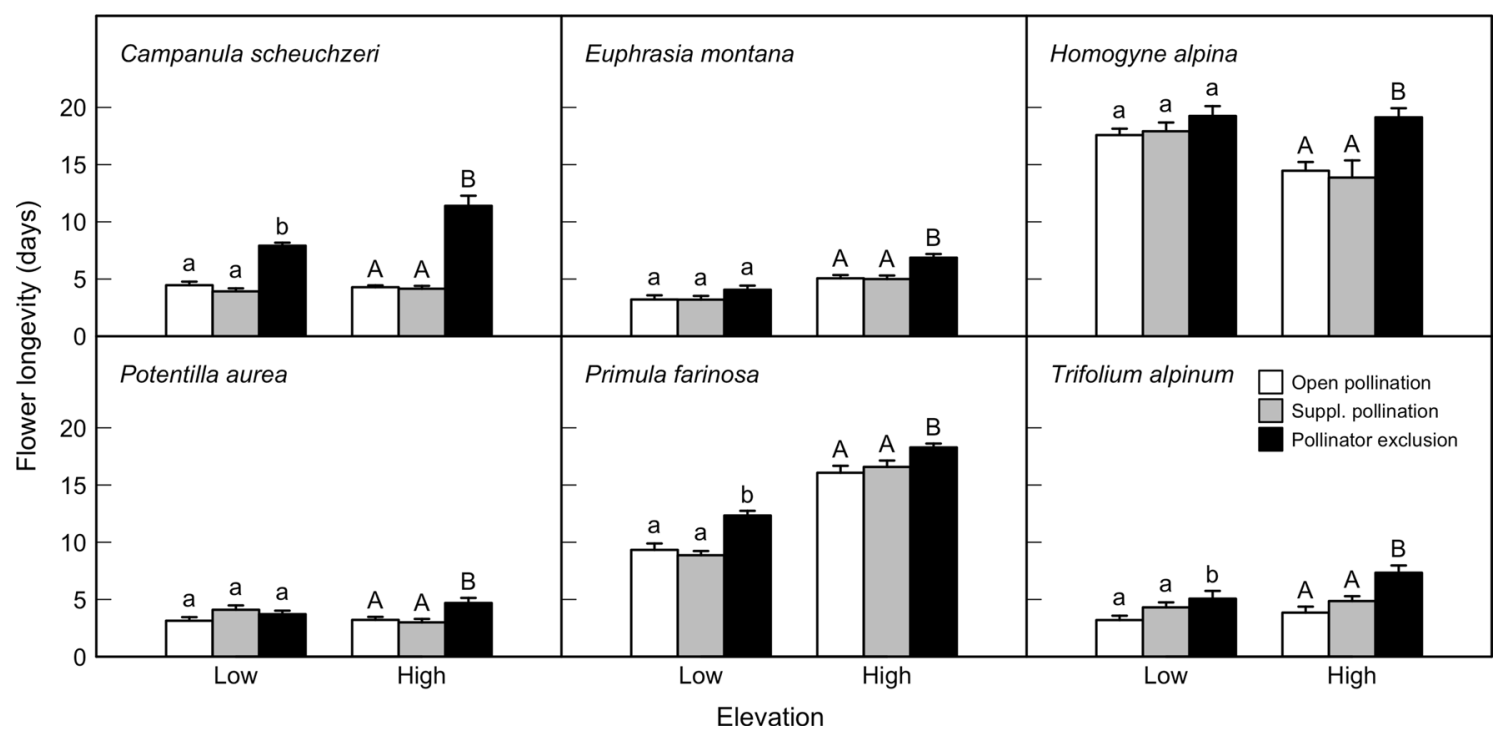

Fig. 1 Flower longevity (mean $\pm \mathrm{SE}$ ) of six alpine species when flowers were either open-pollinated (white bars), supplemental handpollinated (gray bars) or excluded from pollinators (black bars) at low $(1600 \mathrm{~m})$ and high $(2600 \mathrm{~m})$ elevation at the Furka Pass, Central Swiss Alps. Significant differences between control flowers and

was increased in three out of six species at low elevation (Campanula, Primula, and Trifolium), and in all six species at high elevation. For those three species showing significantly increased flower longevity in response to pollinator exclusion at low and high elevation, the increase was noticeably higher at the higher elevation (Fig. 1). Accordingly, ranges of possible flower longevity as measured by the differences between maximum longevity (bagged treatment) and minimum longevity (supplemental pollination treatment) are significantly longer in the high elevation populations (mixed effect model; $P<0.001$; Fig. 3 ), suggesting that plasticity in flower longevity is increased at high elevation. experimentally treated flowers, respectively, are presented from post hoc tests separated for each species and elevation. Bars not sharing the same letters are significantly different at $P<0.05$. Lower case letters indicate the low elevation location and capital letters indicate the high elevation location

\section{Seed production}

Overall, elevation had no consistent effect on seed production across species (significant elevation $\times$ species interaction). Pollination treatment overall significantly affected seed production, but to variable degree among species and between elevations (significant two-way and three-way interactions; Table 2; Fig. S1).

Hand-pollination did not increase seed production for most species at both elevations. Only Campanula and Euphrasia were pollen limited in the lower elevation population (post hoc contrasts, $P<0.05$; Fig. S1) and Homogyne in the higher elevation population. Contrary, 


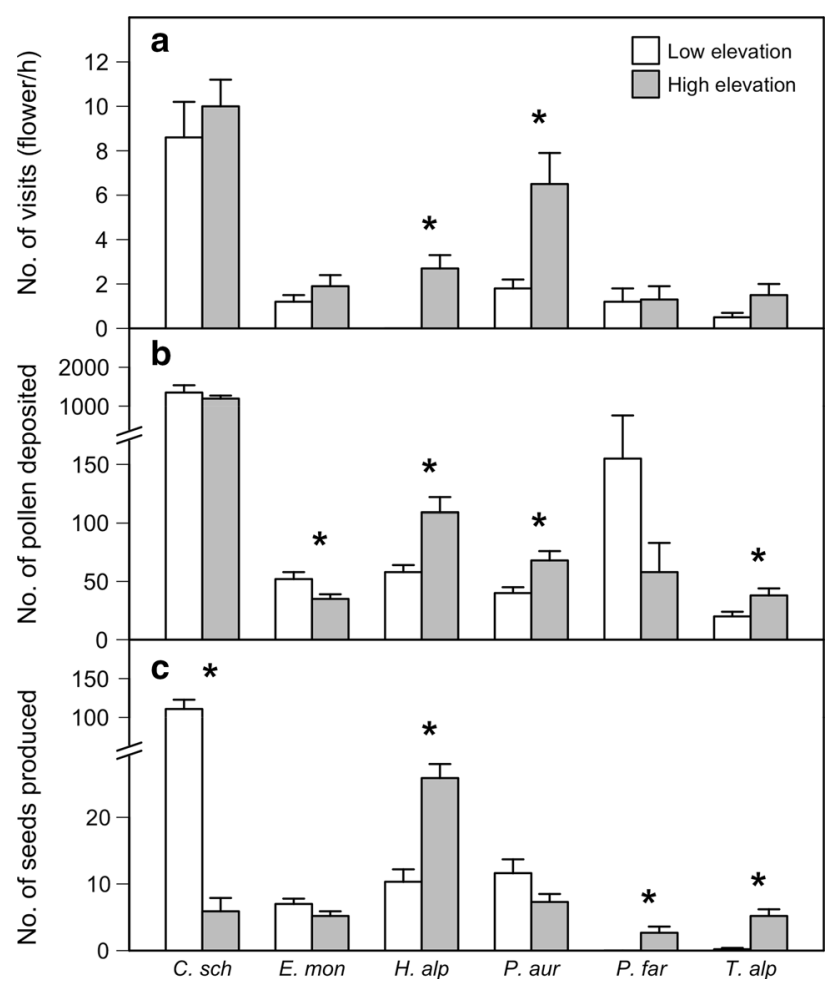

Fig. 2 Hourly visitation rate, pollen deposition, and seed set (mean $\pm \mathrm{SE}$ ) of six alpine species studied at two elevational locations, at 1400 and $2600 \mathrm{~m}$, respectively, at the Furka Pass, Central Swiss Alps. Data for pollen deposition and seed production are pooled from a $24 \mathrm{~h}$ and $48 \mathrm{~h}$ pollination period that flowers were presented to pollinators. Significant differences between populations are indicated from Wilcoxon rank sum tests at $P<0.05$

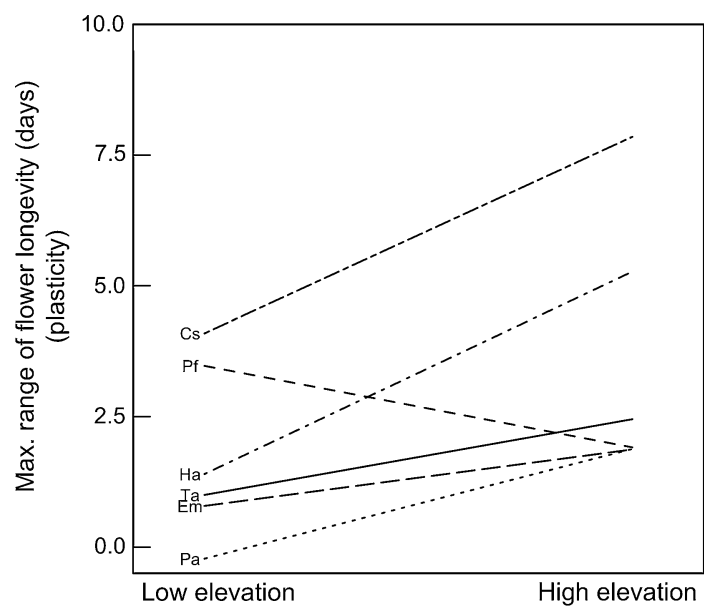

Fig. 3 Differences in the ranges of possible flower longevity in populations of six alpine plant species from low and high elevation at the Furka Pass, Central Swiss Alps $(P<0.001$ for the effect of elevation in a mixed effect model with species as random factor). The maximum range of flower longevity (plasticity) is defined by the difference between the mean longevity measured from flowers under pollinator exclusion and mean flower longevity measured from flowers receiving supplemental hand-pollinations. Species abbreviations are as following: Cs Campanula scheuchzeri, Em Euphrasia montana, Ha Homogyne alpina, Pa Potentilla area, Pf Primula farinosa, Ta Trifolium alpinum pollinator exclusion decreased seed set in almost all populations suggesting high pollinator dependence: the decrease was significant for three species at both elevations ( $\mathrm{Ho}$ mogyne, Potentilla, and Trifolium), and for two species only at the higher elevation (Primula and Euphrasia; post hoc contrasts, $P<0.05$; Fig S1). The seed production of Campanula at high elevation and Primula at low elevation populations was not affected by either pollen supplementation or pollinator exclusion, suggesting other factors than pollinators determine seed production in these populations.

\section{Pollination regime at low and high elevation}

\section{Pollinator activity}

The overall hourly visitation rate was $2.2 \pm 0.4$ (365 flower visits during $2000 \mathrm{~min}$ of observation) at low elevation and $4.3 \pm 0.5$ (806 visits during $1720 \mathrm{~min}$ of observation) at high elevation, indicating an overall higher level of pollinator activity during favorable weather conditions at the higher location. For four of the study species (Campanula, Euphrasia, Primula, Trifolium) visitation rates did not differ between the two elevations, while Potentilla and Homogyne had more visits at the higher elevation (Wilcoxon rank sum test, $P<0.05$; Table S1; Fig. 2a).

The pollinator assemblage varied considerably among species and populations at the two elevations (Table S1). Nevertheless, the most frequent visitors observed at both sites were flies, which accounted for $83 \%$ of all flower visitations at the low and $89 \%$ at the high elevation site. Aside flies, syrphid flies were frequently observed visiting flowers, especially those of Primula and Homogyne, and bumblebees were frequent visitors to flowers of Trifolium.

\section{Pollen deposition after 1 and 2 days of pollination}

Pollen deposition did not generally differ between low and high elevation across species, and the elevational effect varied among species (significant elevation $\times$ species interaction; Table S2). In four species (Campanula, Euphrasia, Potentilla, Trifolium) pollen deposition did not differ between elevations. In Primula pollen deposition was lower at high elevation (GLM, $P=0.015$; Table S3; Fig. 2b), and in Homogyne pollen deposition was higher at the higher elevation (GLM, $P<0.001$; Table S3; Fig. 2b), and this difference tended to be larger when flowers were longer presented to pollinators (GLM, $P=0.099$; Table S3). The duration flowers were presented to pollinators affected pollen deposition differentially at the two elevations across species as indicated by a significant elevation $\times$ pollination duration interaction (GLM, $P<0.01$; Tables S2, S3). However, pollen deposition significantly increased with duration of possible pollinator visitation only 
in flowers of Potentilla (GLM, $P=0.012$; Table S3), with a marginal significantly larger increase at the higher elevation (GLM, $P=0.051$; Table S3; Fig. 2b), whereas no difference with duration flowers were accessible for pollination was found in the five other species.

\section{Seed production after 1 and 2 days of pollination}

Elevation significantly affected seed production, but the difference was not consistent between populations at the two elevations among the six species (significant effect of elevation and elevation $\times$ species interaction; Table S2). Seed production was similar at both elevations in Euphrasia, Potentilla, and Trifolium, while it was increased compared to low elevation in Homogyne and Primula, and decreased at high elevation compared to low elevation in Campanula (GLM, all $P<0.001$; Table S3; Fig. 2c). For most populations seed production did not differ with more time available for pollination (Table S2). The duration of pollinator exposure increased seed production only in Potentilla similarly at both low and high elevation (GLM, $P=0.076$; Table S3), and in Homogyne at low and high elevation (GLM, $P<0.002$; Table S3) but with a larger effect in the high elevation population (GLM, $P=0.016$; Table S3).

\section{Discussion}

\section{Flower longevity in response to pollination}

Optimal flower longevity should be determined by the balance of reproductive success and costs of floral development and maintenance. A negative correlation of flower longevity with spatial or temporal gradients of declining pollination intensity has frequently been observed at the level of flowering plant communities (Arroyo et al. 1981; Primack 1985, Blionis et al. 2001; Fabbro and Körner 2004), populations of single species (Bingham and Orthner 1998; Yasaka et al. 1998; Blionis et al. 2001; Blionis and Vokou 2001; Giblin 2005; Egisdottir and Thorhallsdottir 2006; Lundemo and Totland 2007) and individual flowers (Devlin and Stephenson 1984; Richardson and Stephenson 1989; Evanhoe and Galloway 2002; Castro et al. 2008), suggesting adaptation of mean flower longevity among populations of contrasting pollination environments, and high plasticity of individual flower longevity in response to variable pollination success within population. However, whether phenotypic plasticity itself is of advantage in highly stochastic pollination environments has rarely been investigated. In the present study, we experimentally tested the plasticity of flower longevity in response to the intensity of pollination at the level of populations (at different elevation) and at the level of individual flowers (different pollination treatment) in natural populations of six common alpine species. We expected, first, a general increase in flower longevity for all the six species at the higher elevation, and second, an even stronger increase of flower longevity when pollination was prohibited in the high elevation populations compared to the low elevation populations. The results of this study indicate that all six studied species showed pollination-induced variability in flower longevity, with expected shorter flower longevities under supplemental pollination and elongated flower longevities under experimental pollination failure. And despite there was no general trend for increased flower longevity in populations at high elevation, the response of flower longevity to variation in the intensity of pollination was more variable in the high elevation populations compared to populations at the low elevation (Fig. 3).

Across all six studied species, the realized longevity of naturally pollinated flowers was larger at the high elevation location (mean 7.8 days) than the realized flower longevity at the low elevation location (mean 6.8 days). Nevertheless, this trend was not consistent among species, and thus, our study does not support the predicted general increase of flower longevity at higher elevations (Ashman and Schoen 1994) at the level of individual species. Such differences in within-species variation in flower longevity were also detected in previous studies: Giblin (2005) and Bingham and Orthner (1998) clearly confirmed the predicted pattern for populations of Campanula rotundifolia L., whereas studies on Gentiana straminea Maxim. (Duan et al. 2007), Dryas octopetala (Lundemo and Totland 2007) and Chaetanthera euphrasioides (DC.) Meigen (Arroyo et al. 2006) did not find support for an increase in flower longevity with increasing elevation. Further, Blionis and Vokou (2001) reported an increase of 0.2 days every $100 \mathrm{~m}$ for the genus Campanula, but at the species level this trend only held true for some species. Thus, we propose that enhanced flower longevity in high elevation environments is a consistent pattern only at the overall community or genus level, and depends on the species composition. Under environmental conditions that accompany low or unpredictable pollination intensities such as in alpine habitats, flowers with an increased longevity should be favored (Torres-Diaz et al. 2011; Marques and Draper 2012), and thus, a shift to species with long-living flowers is likely to occur with increasing elevation (Arroyo et al. 2006).

We detected no significant difference in flower longevity between naturally open-pollinated and hand-pollinated flowers in any of the studied populations, suggesting that the realized flower longevity of naturally pollinated flowers was close to the minimal flower longevity, and that the intensity of pollination was sufficiently high at low and high elevation. In fact, only two of our studied populations were pollen limited (Campanula and Euphrasia at the low elevation), 
and we did not observe any difference between the two pollination environments in terms of pollinator activity and efficiency and effectivity of pollinators (see below). Similar experiments with Campanula rotundifolia in the Rocky Mountains (Giblin 2005) and Campanula uniflora in Greenland and Iceland (Ægisdottir and Thorhallsdottir 2006) found shortening of flower longevity when flowers were supplemented with additional pollen. Unfortunately, neither of these two studies simultaneously documented pollinator abundance and activity, but assumed environmental constraints for pollinators and limitation of pollination as it is otherwise typical for arctic and alpine regions.

As expected flower longevity was significantly increased by the exclusion of pollinators, that is, pollination failure. This effect is well supported for other insect-pollinated species studied in high mountain regions. For example, in a study on Mount Olympus, Greece, Blionis and Vokou (2001) reported a three- to fivefold increase in flower longevity for several Campanula species when flowers were prevented from pollination. Similarly, Duan et al. (2007) measured a considerable increase of flower longevity in two populations of Gentiana straminea at two different elevational sites on the Qinghai-Tibetan Plateau when pollinating bumblebees were excluded. Interestingly, in our experiment, flower longevity was increased under pollinator exclusion only in three of the six species at the low elevation (Campanula, Primula and Trifolium), whereas it was increased in all the six species in response to pollinator exclusion at the high elevation location. Among-population variation in flower longevity as a response to pollination intensity was also reported for Campanula rotundifolia, whereby male and female phases accounted differently to the overall parallel increase of flower longevity at two different elevational sites (Giblin 2005). Thus, pollination-induced flower longevity may vary among populations occurring in different pollination environments, with higher plasticity as pollination becomes increasingly variable and unreliable at higher elevations.

Among-population variation in the response of flower longevity to pollination may also arise from differences in abiotic conditions such as temperatures and water availability between low and high elevational environments. Floral metabolic rates and development are faster under warm temperatures (Primack 1985), thereby potentially limiting the capacity that flowers can respond to pollination at low compared to high elevation, i.e., warm and cold temperatures, respectively. Thus, longer flower longevities may be the result of decelerated flower development at high elevation disregarding of any changes in the pollination environment (Arroyo et al. 1981; Rathcke 2003), but nevertheless ameliorates low pollination condition in the alpine (Arroyo et al. 2013). Likewise, water availability has been experimentally shown to account for population differences in flower longevity in a recent study by Teixido and Valladares (2015). Thus, differences in both pollination and environmental conditions are important factors influencing variation in realized flower longevity among populations. Because in the present study we did not incorporated differences in environmental conditions between the two elevational locations, we cannot rule out that other particular abiotic factors have contributed to the observed variation in flower longevity. However, our data provide clear evidence that realized flower longevity is a highly plastic response to pollinations intensity, and particularly advantageous in highly stochastic pollination environments.

\section{Pollination environment at low and high elevation}

Our assessment of the actual pollination environment in the low and high elevation population trough estimates of pollinator activity, pollinator efficiency and pollinator effectiveness does not support a decrease in pollination intensity in the populations at the higher elevation, at least under good weather conditions. Low pollinator availability has been reported for multiple high mountains around the world (Arroyo et al. 1982, 1985; McCall and Primack 1992; Totland 1994b; Bingham and Orthner 1998), but it might not necessarily characterize all alpine regions, at least not to the same degree (Arroyo et al. 2006). In our study, pollinator visitation rates were consistently higher for the populations at high elevation compared to the low elevation populations (4.3 and $2.2 \mathrm{~h}^{-1}$, respectively). High pollinator activity and visitation frequencies are also reported from the Swiss Alps for the popular alpine species Edelweiss, Leontopodium alpinum L. (Erhardt 1993), the Quinghai Tibetan Plateau (Duan et al. 2007), and alpine Norway (Lundemo and Totland 2007). Further, the similarity in pollinator visitations between our two study locations did also translate into equal stigmatic pollen loads indicating that pollinators were similarly efficient at both locations. However, the significant elevation $\times$ pollination duration interaction suggests that temporal variation in pollination was considerably higher in the high elevation populations then it was in the low elevation populations. Finally, the elevation effect on pollination effectivity varied among species, but only Campanula showed a markedly lower seed production in the high elevation population. However, hand-pollinations did not increase seed number, suggesting environmental constraints limiting seed production in this population. Resource rather than pollen limitation for plant reproduction is not uncommon in alpine environments and has been found for numerous other alpine species (Cambell and Hamala 2003; Totland 1997; Totland and Eide 1999, see GarciaCamacho and Totland 2009 for a more general discussion). Further, Kudo and Molau (1999)found similar fertilization 
rates, but significantly higher seed abortion rates when comparing high elevation with low elevation populations of Astragulus alpinus $\mathrm{L}$. in northern Sweden.

In summer 2009, we experienced uncommonly high temperatures and low precipitation almost throughout the entire study season at the Furka Pass (E. Hiltbrunner, pers. communication), presumably accounting for the high pollinator activity found at both elevations. Such constant favorable weather conditions throughout the flowering season are rather rare in alpine regions, and data covering multiple flowering seasons would be needed to confirm a constantly high pollinator activity in this alpine habitat. While spatial variation in plant-pollinator interactions could promote the divergent evolution of floral characters, temporal variation in interactions would limit its potential (Vanhoenacker et al. 2006). Thus, an evolutionary adaptation of a trait, as in our study increased flower longevity, is only likely if there is a constant selective force (Kawecki and Ebert 2004) such as low pollination intensity, rather than large temporal fluctuations of pollinator availability. Conversely, large temporal variation in the pollination environment, as it has been demonstrated for other mountain regions (Duan et al. 2007), could promote a higher plasticity of flower longevity in the response to pollination intensity as adaptation to efficiently balance the trade-off between costs of flower maintenance and reproductive efforts.

\section{Conclusion}

Our results indicate that in alpine plants flower longevity is not in general increased in populations occurring at high elevation compared to populations at lower elevation, but instead, populations at high elevation show a higher phenotypic plasticity in response to pollination. Increased flower longevity maintains the opportunity for fertilization under unpredictable pollination conditions, but could also have reproductive costs for the production of offspring (Castro et al. 2008). We suggest that pollination-induced variability of flower longevity is more important in high elevation populations than in lowland populations, since it allows plants to efficiently cope with the unpredictable availability of pollinators in alpine environments for two reasons. First, the capacity to maintain flowers for longer time compensates for low pollinator activity in unfavorable periods by increasing the likelihood of pollinator visitations, the number of pollen grains that are transferred, and, finally, the number of seeds that are produced, i.e. reproductive success. Second, comparable shorter flower longevity in favorable periods, when pollinator activity is high, should be advantageous: On the one hand, rapid senescence saves redundant costs of maintaining flowers when the reproductive functions are already fulfilled
(Stead 1992), and on the other hand, flower senescence can guide pollinators to virgin flowers (vanDoorn 1997), what is likely to be even more important in alpine habitats. Thus, increased plasticity of flower longevity at high elevation may compensate for low pollinator activity during unfavorable periods, ensuring a minimal seed production and saving resources for suitable periods. We conclude that genotypes with a high variability in flower longevity are of advantage in highly stochastic pollination environments, and that selection should favor and maintain a higher phenotypic plasticity of flower longevity in populations of alpine species at high elevation.

Acknowledgments We would like to specially thank Erika Hiltbrunner, Nicole Inauen, Esther Liescher, and José Monteiro for their support with fieldwork and logistics, and we acknowledge Sonja Wipf and two anonymous reviewers for helpful comments on an earlier version of the manuscript.

\section{Complaince with Ethical Standard}

Conflict of interest The authors declare that they have no conflict of interest.

Declaration of authorship JT and JS conceived and designed the research. JT conducted the experiments, analyzed the data and wrote the manuscript. Both authors contributed to writing and approved the manuscript.

Open Access This article is distributed under the terms of the Creative Commons Attribution 4.0 International License (http:// creativecommons.org/licenses/by/4.0/), which permits unrestricted use, distribution, and reproduction in any medium, provided you give appropriate credit to the original author(s) and the source, provide a link to the Creative Commons license, and indicate if changes were made.

\section{References}

Ægisdottir HH, Thorhallsdottir TE (2006) Breeding system evolution in the Arctic: a comparative study of Campanula uniflora in Greenland and Iceland. Arct Antarct Alp Res 38:305-312

Arroyo MTK, Armesto JJ et al (1981) Plant phenological patterns in the High Andean Cordillera of Central Chile. J Ecol 69:205-223

Arroyo MTK, Primack R et al (1982) Community studies in pollination ecology in the High Temperate Andes of Central Chile. I. Pollination mechanisms and altitudinal differences. Am J Bot 69:82-97

Arroyo MTK, Armesto JJ et al (1985) Community studies in pollination ecology in the High Temperate Andes of Central Chile. II. Effect of temperature on visitation rates and pollination possibilities. Plant Syst Evol 149:187-203

Arroyo MTK, Munoz MS et al (2006) Erratic pollination, high selfing levels and their correlates and consequences in an altitudinally widespread above-tree-line species in the High Andes of Chile. Acta Oecol 30:248-257

Arroyo MTK, Dudley LS et al (2013) Temperature-driven flower longevity in a high-alpine species of Oxalis influences reproductive assurance. New Phytol 200:1260-1268

Ashman TL, Schoen DJ (1994) How long should flowers live? Nature 371:788-791 
Ashman TL, Schoen DJ (1997) The costs of floral longevity in Clarkia tembloriensis: an experimental investigation. Evol Ecol 11:289-300

Beattie AJ (1971) A technique for the study of insect-borne pollen. Pan-Pacific Entomologist 47:82

Billings WD (1974) Arctic and alpine vegetation: plant adaptations to cold summer climates. In: Ives JD, Barry RG (eds.) Arctic and alpine environments. Methuen, p 403-443

Bingham RA, Orthner AR (1998) Efficient pollination of alpine plants. Nature 391:238-239

Blionis GJ, Vokou D (2001) Pollination ecology of Campanula species on Mt Olympos, Greece. Ecography 24:287-297

Blionis GJ, Halley JM et al (2001) Flowering phenology of Campanula on Mt Olympos, Greece. Ecography 24:696-706

Cambell DR, Hamala KJ (2003) Resource and pollen limitations of lifetime seed production in a natural plant population. Ecology 74:1043-1051

Castro S, Silveira P et al (2008) Effect of pollination on floral longevity and costs of delaying fertilization in the out-crossing Polygala vayredae Costa (Polygalaceae). Ann Bot 102:1043-1048

Clark MJ, Husband BC (2007) Plasticity and timing of flower closure in response to pollination in Chameron angustifolium (Onagraceae). Int J Plant Sci 168:619-625

Dafni A, Kevan PG et al (2005) Practical pollination biology. Environquest Ltd, Cambridge

R Development Core Team (2008) R: A language and environment for statistical computing. R Foundation for Statistical Computing, Vienna

Devlin B, Stephenson AG (1984) Factors that influence the duration of the staminate and pistillate phases of Lobelia cardinalis flowers. Bot Gaz 145:323-328

Duan YW, Zhang TF et al (2007) Interannual fluctuations in floral longevity, pollinator visitation and pollination limitation of an alpine plant (Gentiana straminea Maxim., Gentianaceae) at two altitudes in the Qinghai-Tibetan Plateau. Plant Syst Evol 267:255-265

Elberling H (2001) Pollen limitation of reproduction in a subarcticalpine population of Diapensia lapponica (Diapensiaceae). Nord J Bot 21:277-282

Erhardt A (1993) Pollination of the Edelweiss, Leontopodium alpinum. Bot J Linn Soc 111:229-240

Evanhoe L, Galloway LF (2002) Floral longevity in Campanula americana (Campanulaceae): a comparison of morphological and functional gender phases. Am J Bot 89:587-591

Fabbro T, Körner C (2004) Altitudinal differences in flower traits and reproductive allocation. Flora 199:70-81

Garcia-Camacho R, Totland O (2009) Pollen limitation in the Alpine: a meta-analysis. Arct Antarct Alp Res 41:103-111

Giblin DE (2005) Variation in floral longevity between populations of Campanula rotundifolia (Campanulaceae) in response to fitness accrual rate manipulation. Am J Bot 92:1714-1722

Gomez JM (2002) Self-pollination in Euphrasia willkommii Freyn (Scrophulariaceae), an endemic species from the alpine of the Sierra Nevada (Spain). Plant Syst Evol 232:63-71

Kawecki TJ, Ebert D (2004) Conceptual issues in local adaptation. Ecol Lett 7:1225-1241

Kudo G, Molau U (1999) Variations in reproductive traits at inflorescence and flower levels of an arctic legume, Astragalus alpinus L.: comparison between a subalpine and an alpine population. Plant Species Biol 14:181-191

Liebst B, Schneller J (2005) How selfing and intra- and interspecific crossing influence seed set, morphology and ploidy level in Euphrasia: an experimental study of species occurring in the Alps of Switzerland. Plant Syst Evol 255:193-214

Lundemo S, Totland O (2007) Within-population spatial variation in pollinator visitation rates, pollen limitation on seed set, and flower longevity in an alpine species. Acta Oecol 32:262-268
Marques I, Draper D (2012) Pollination activity affects selection on floral longevity in the autumnal-flowering plant, Narcissus serotinus L. Botany-Botanique 90:283-291

McCall C, Primack RB (1992) Influence of flower characteristics, weather, time of day, and season on insect visitation rates in three plant communities. Am J Bot 79:434-442

Olesen JM, Jordano P (2002) Geographic patterns in plant-pollinator mutualistic networks. Ecology 83:2416-2424

Pinheiro J, Bates D et al (2009) nlme: Linear and nonlinear mixed effects models. R package version 3.1-96. R Foundation for Statistical Computing, Vienna

Primack RB (1985) Longevity of individual flowers. Annu Rev Ecol Syst 16:15-37

Primack RB, Inouye DW (1993) Factors affecting pollinator visitation rates-a biogeographic comparison. Curr Sci 65:257-262

Rathcke BJ (2003) Floral longevity and reproductive assurance: seasonal patterns and an experimental test with Kalmia latifolia (Ericaceae). Am J Bot 90:1328-1332

Richardson TE, Stephenson AG (1989) Pollen removal and pollen deposition affect the duration of the staminate and pistillate phases in Campanula rapunculoides. Am J Bot 76:532-538

Schoen DJ, Ashman TL (1995) The evolution of floral longevityresource-allocation to maintenance versus construction of repeated parts in modular organisms. Evolution 49:131-139

Stead AD (1992) Pollination induced flower senescence. Plant Growth Regul 11:13-20

Stenström M, Molau U (1992) Reproductive ecology of Saxifraga oppositifolia-phenology, mating system, and reproductive success. Arct Alp Res 24:337-343

Teixido AL, Valladares F (2015) Temperature-limited flower longevity in the large-flowered Mediterranean shrub Cistus ladanifer (Cistaceae). Int J Plant Sci 176:131-140

Torres-Diaz C, Gomez-Gonzalez S et al (2011) Extremely long-lived stigmas allow extended cross-pollination opportunities in a High Andean plant. PLoS One 6:e19497. doi:10.1371/journal.pone. 0019497

Totland O (1994a) Intraseasonal variation in pollination intensity and seed set in an alpine population of Ranunculus acris in southwestern Norway. Ecography 17:159-165

Totland O (1994b) Influence of climate, time of day and season, and flower density on insect flower visitation in alpine Norway. Arct Alp Res 26:66-71

Totland O (1997) Limitations on reproduction in alpine Ranunculus acris. Can J Bot 75:137-144

Totland O (2001) Environment-dependent pollen limitation and selection on floral traits in an alpine species. Ecology 82:2233-2244

Totland O, Eide W (1999) Environmentally-dependent pollen limitation on seed production in alpine Ranunculus acris. Ecoscience 6:173-179

Totland O, Sottocornola M (2001) Pollen limitation of reproductive success in two sympatric alpine willows (Salicaceae) with contrasting pollination strategies. Am J Bot 88:1011-1015

vanDoorn WG (1997) Effects of pollination on floral attraction and longevity. J Exp Bot 48:1615-1622

Vanhoenacker D, Agren J et al (2006) Spatio-temporal variation in pollen limitation and reproductive success of two scape morphs in Primula farinosa. New Phytol 169:615-621

Warren SD, Harper KT et al (1988) Elevational distribution of insect pollinators. Am Midl Nat 120:325-330

Yasaka M, Nishiwaki Y et al (1998) Plasticity of flower longevity in Corydalis ambigua. Ecol Res 13:211-216

Zuur AF, Ieno EN et al (2009) Mixed effects models and extensions in ecology with R. Springer, New York, p 574 